\title{
DESENVOLVIMENTO DOS RELACIONAMENTOS ENTRE COMPRADOR E VENDEDOR
}

RESUMO

A teoria e a prática do marketing se concentraram persistentemente nas trocas entre compradores e vendedores. Infelizmente, a maior parte da pesquisa e um número excessivo de estratégias de marketing tratam as trocas entre compradores e vendedores como eventos singulares e não como relacionamentos contínuos. Os autores descrevem um arcabouço para o desenvolvimento de relacionamentos entre comprador e vendedor que permite uma visão privilegiada para a formulação de estratégias de marketing e para o estímulo a novas áreas de pesquisa.

\section{F. Robert Dwyer}

University of Cincinnati

\section{Paul H. Schurr}

University at Albany

\section{Sejo Oh}

Yonsei University

ABSTRACTM arketing theory and practice have focused persistently on exchange between buyers and sellers. U nfortunately, most of the research and too many of the marketing strategies treat buyer-seller exchanges as discrete events, not as ongoing relationships. The authors describe a framework for developing buyer-seller relationships that affords a vantage point for formulating marketing strategy and for stimulating new research directions.

PALAVRAS-CHAVE Trocas entre comprador e vendedor, estratégias de marketing, desenvolvimento de relacionamento compradorvendedor, pesquisa em marketing.

KEYORDS Exchange between buyer and seller, marketing strategies, developing buyer-seller relationships, marketing research. 
Resumindo 15 anos de debates sobre o domínio conceitual do marketing, Hunt (1983a, p. 9) conclui que "[...] o foco principal do marketing é a relação de troca" (veja também Ferber, 1970; Kotler, 1972; Kotler e Levy, 1969; Kotler e Zaltman, 1971; Luck, 1969, 1974). A relativa permanência dessa visão foi instituída pelos recentes avanços teóricos a que levou. São exemplos o arcabouço de Frazier (1983a) de trocas interoganizacionais, a teoria das trocas de Bagozzi $(1975,1979)$ e o modelo contingencial de vendas de Weitz (1981). As trocas também representam um papel de destaque no arcabouço de economia política (Achrol, Reve e Stern, 1983; Arndt, 1983; Stern e Reve 1980) e em mais um sem-número de estudos empíricos especial izados.

Cada um dos trabalhos citados depende da noção de troca por causa de quatro benefícios conceituais fundamentais. Em primeiro lugar, as trocas servem como eventos focais entre duas ou mais partes. Segundo, fornecem um importante quadro de referência para a identificação da rede social de pessoas e empresas participantes de sua formação e execução. Terceiro, dão a oportunidade de examinar o domínio dos objetos ou entidades físicas que são transferidos. Finalmente, e mais importante, na qualidade de eventos críticos do mercado, permitem um estudo detido das condições antecedentes e dos processos da troca entre comprador e vendedor.

A pesar da importância geral mente atribuída ao conceito de troca, a pesquisa em marketing praticamente ignorou o aspecto do relacionamento do comportamento comprador-vendedor por tender a tratar as transações como eventos isolados. A falta de atenção às condições e processos precedentes das relações de troca comprador-vendedor representa uma omissão séria no desenvolvimento do conhecimento em marketing.

Os relacionamentos entre comprador e vendedor podem assumir muitas formas diferentes. Arndt (1979) observou a tendência da troca organizacional a ficar circunscrita por associações de longo prazo, relações contratuais e propriedade conjunta. Apelidando esses fenômenos de "mercados domesticados", ele argumentou que dentro de tais relacionamentos "as transações são planejadas e administradas em vez de serem realizadas caso a caso" (Arndt, 1979, p. 70).

Arndt deu a correta ênfase à predominância dos relacionamentos de troca nos mercados industrial e institucional, mas o conceito de gestão de relacionamento também pode ser aplicado aos mercados de consumo. A longa lista de elos organizacionais no marketing das empresas fornecida por Arndt contrasta com sua ilustração aparentemente perfunctória dos relacio- namentos com consumidores. "[...] cooperativas de consumidores na Grã-Bretanha e na Escandinávia, [ ... ] clubes de livros ou discos, [...] ingressos para temporadas esportivas ou de artes e, de certa forma, assinaturas de jornais e revistas e cartões de crédito" (Arndt, 1979, p. 71). Vamos anotar outros comportamentos comuns entre os consumidores: programas de milhagem, títulos de clubes religiosos e profissionais, contratação de serviços pessoais (advogados, barbeiros, médicos) e os elos implícitos subjacentes à fidelidade a marcas. Assim, tanto o marketing dirigido às empresas quanto 0 marketing dirigido ao consumidor se beneficiam da atenção a condições que favoreçam elos relacionais capazes de levar à reiteração de negócios.

\section{OBJETIVOS}

N ossa meta maior é delinear um arcabouço para o desenvolvimento de relações comprador-vendedor. Em primeiro lugar, comparamos rapidamente trocas singulares e relacionais utilizando conceitos do direito contratual moderno. Como o conceito de troca singular, segundo o direito contratual, é uma ficção idealizada, sugerimos áreas e questões problemáticas em que pareça recomendável desconsiderar ou enfatizar as dimensões relacionais. Partimos do interessante trabalho de Macneil (1980) para indicar as propriedades relacionais que possam ser rel evantes nas trocas comprador-vendedor. Em seguida, após uma breve conjectura sobre os custos e benefícios da troca relacional, propomos um modelo em cinco fases segundo o qual se formam as relações. Usando os trabalhos de Scanzoni (1979), Thibaut e Kelley (1959), e outros teóricos das trocas, destacamos as transições hipotéticas e as principais distinções entre as fases. Finalmente, baseamo-nos no arcabouço para propor uma agenda de pesquisa e delinear três facetas cruciais do gerenciamento das relações comprador-vendedor.

\section{TROCAS SINGULARES E RELACIONAIS}

\section{Transações singulares}

0 conceito de transação singular é o fundamento sobre o qual se constroem os conceitos de relacionamento. Segundo Macneil (1980), o arquétipo da transação singular se manifesta como dinheiro de um lado, e do outro como uma mercadoria facilmente mensurável. Em suas palavras, 
[...] singularidade é a separação entre uma transação e tudo mais que haja entre os participantes no mesmo momento, antes e depois. Sua [forma pura], jamais realizada na vida, surge quando nada mais há, houve ou haverá entre as partes. (MACNEIL, 1980, p. 60).

Observe que o conceito de transação singular exclui especificamente el ementos relacionais. Transações singulares se caracterizam por comunicação muito limitada e conteúdo exíguo. A identidade das partes de uma relação precisa ser desconhecida, caso contrário surgem relações. Uma compra única de gasolina genérica num posto sem bandeira localizado numa cidade que não é a do comprador e cujo pagamento se dê em dinheiro se aproxima de uma transação singular.

\section{Troca relacional}

A base de uma forte clientela (ou, do ponto de vista do comprador, de uma equipe confiável de fornecedores) está no distanciamento em relação à âncora da singularidade. Argumentamos que uma clientela (ou base de fornecedores) forte depende da natureza do contrato relacional entre um comprador e um vendedor.

Macneil $(1978,1980)$ diferencia transações singulares de contratos relacionais, troca relacional, com base em diversas dimensões-chave. Da maior importância é o fato de que a troca relacional se dá com o tempo: cada transação precisa ser vista em termos de seu histórico e do futuro para ela previsto. As bases da colaboração futura podem ser sustentadas por premissas implícitas e explícitas, confiança e planejamento. É de se esperar que os participantes de uma troca relacional obtenham satisfação complexa, pessoal e não econômica, e se envolvam em trocas sociais. Como os deveres e o desempenho são relativamente complexos e ocorrem ao longo de um período de tempo prolongado, as partes podem dirigir muitos esforços a uma definição e a uma mensuração cautelosa dos itens de troca. Tercei ros podem ser convocados para adjudicar, e podem ser concebidos outros mecanismos personalizados de colaboração e solução de conflitos.

O Quadro 1 resume a caracterização dada por $M$ acneil dos arquéti pos polares singulares e relacionais de troca em 12 dimensões obrigacionais. De acordo com nossa discussão anterior, por exemplo, um consumidor poderia comprar pêssegos na feira, ou um quitandeiro poderia comprá-los às sacas de qualquer uma dentre diversas fontes. Os produtos podem ser facilmente avaliados, pagos em dinheiro e levados embora. Não há negociação prolongada, o pagamento em dinheiro e à vista consuma a transação, e a situação de dependência mútua logo cessa. Todas as características situacionais e processuais se aproximam das de uma transação singular.

O Quadro 1 indica que os aspectos relacionais começam a surgir quando o comprador paga em cheque ou quando o vendedor programa a entrega para a semana seguinte. O u seja, a dependência se prolonga, a prestação é menos óbvia, a incerteza leva a uma comunicação mais aprofundada, surgem os rudimentos de planejamento cooperativo e a antecipação de conflitos, e as expectativas de confiabilidade podem ser afetadas por características pessoais.

Embora uma revisão detalhada das dimensões de M acneil fuja ao alcance deste artigo, o Q uadro 1 atende a dois fins importantes. Primeiro, dramatiza a multidimensionalidade da troca. No domínio do marketing, nossas eventuais necessidades de teoria e prática podem exigir menos do que 12 dimensões, mas 0 foco evidentemente limitado da pesquisa anteriormente produzida (sobre relações de poder e pessoais) reflete uma consideração incompleta das propriedades da troca. Assim, a caracterização dos arquétipos polares em 12 dimensões nos leva a considerar amplos arranjos de formas transacionais diversas.

Em segundo lugar, o Quadro 1 deve enfatizar a necessidade de fazer distinções "práticas" entre trocas singulares e relacionais, especialmente no atual estado embrionário da investigação. Como estabelecem nossas transações exemplares da feira e do quitandeiro, o concei to de troca instantânea entre parceiros anônimos que jamais interagirão no futuro é um modelo abstrato que não ocorre na realidade. M esmo o mais simples dos modelos de troca singular deve postular aquilo que Macneil (1980) chama de "matriz social": um meio eficaz de comunicação, um sistema que evite homicídios e furtos, uma moeda e um mecanismo para forçar o cumprimento de promessas. Assim, do ponto de vista do direito contratual, alguns elementos de "relacionamento" encontram-se subjacentes a todas as transações.

Esse argumento não quer dizer que devamos descartar o conceito de troca singular. Com efeito, Goldberg (1979) afirma que tratar a troca como uma transação singular dirige a atenção a três questões importantes: (1) como os agentes econômicos fazem escol has dentre um conjunto de al ternativas; (2) que resultados de mercado decorrerão das escol has simultâneas dos agentes individuais; e (3) como os resultados dependem da estrutura das alternativas (competição)? 
Quadro 1 - Comparação entre transações singulares e trocas relacionais.

\begin{tabular}{|c|}
\hline ELEMENTOS CONTRATUAIS \\
\hline CARACTERÍSTICAS SITUACIONAIS \\
\hline $\begin{array}{l}\text { Momento da troca (início, duração e en- } \\
\text { cerramento) }\end{array}$ \\
\hline $\begin{array}{l}\text { Número de partes (entidades que participam } \\
\text { de algum aspecto do processo de troca) }\end{array}$ \\
\hline $\begin{array}{l}\text { Obrigações (três aspectos: fontes de conteú- } \\
\text { do, fontes de obrigação e especificidade) }\end{array}$ \\
\hline $\begin{array}{l}\text { Expectativas quanto ao relacionamento } \\
\text { (especialmente em relação a conflitos de } \\
\text { interesses, prospectos de união e proble- } \\
\text { mas em potencial) }\end{array}$ \\
\hline
\end{tabular}

\section{CARACTERISTICAS PROCESSUAIS}

Relações pessoais primárias (interação e comunicação sociais)

Solidariedade contratual (regulação do comportamento de troca para garantir prestação)

Transferibilidade (a capacidade de transferir direitos, obrigações e satisfações para outras partes)

Cooperação (especialmente esforços conjuntos de prestação e planejamento)

Planejamento (o processo e os mecanismos para lidar com mudança e conflitos)

Mensuração e especificidade (cálculo e ajuste da troca)

Poder (a capacidade de impor sua vontade a outros)

Divisão de benefícios e ônus (a medida do compartilhamento de benefícios e ônus)
TRANSAÇÕES SINGULARES

Início distinto, breve duração e término abrupto pelo desempenho

\section{Duas partes}

Conteúdo decorrente de ofertas e alegações simples, obrigações decorrentes de crenças e costumes (aplicação externa) e obrigações padronizadas

Esperam-se conflitos de interesse (metas) e baixa união, mas não se esperam problemas futuros porque o $\mathrm{pa}$ gamento em dinheiro e à vista com contraprestação instantânea exclui a interdependência futura.

Relacionamento pessoal mínimo; predominam comunicações ritualísticas

Regidas por normas sociais, regras, etiqueta e perspectivas de benefício pessoal

Transferibilidade total; não importa quem cumpra a obrigação contratual

Sem esforços conjuntos

Foco primário na substância da troca; não se antevê futuro

Pouca atenção dada a mensuração e especificações; a prestação é óbvia

0 poder pode ser exercido quando são feitas promessas até que executadas

Forte divisão de benefícios e ônus compartimentalizados; alocação exclusiva às partes
TROCA RELACIONAL

0 início vem de avenças anteriores; a troca é mais duradoura, refletindo um processo contínuo

Muitas vezes há mais de duas partes envolvidas no processo e na governança de troca

0 conteúdo e as fontes de obrigações são promessas feitas na relação, mais usos e costumes e a lei; as obrigações são personalizadas, detalhadas e administradas no contexto da relação

Conflitos de interesses e dificuldades futuras são contrabalançados por confiança e esforços de união

Obtêm-se importantes satisfações pessoais e não econômicas; são utilizadas comunicações tanto formais quanto informais

Maior ênfase sobre a regulação jurídica e a auto-regulação; satisfações psicológicas levam a ajustes internos

Transferibilidade limitada; a troca é fortemente dependente das identidades das partes

Esforços conjuntos ligados às prestações e ao planejamento ao longo do tempo; 0 ajuste com o passar do tempo é endêmico

Foco significativo sobre o processo de troca; planejamento detalhado de trocas futuras em novos ambientes para atender às metas em mutação; abundam premissas tácitas e explícitas

Importante atenção dada a mensuração, especificação e quantificação de todos os aspectos prestacionais, inclusive benefícios futuros e psíquicos

A maior interdependência aumenta a importância da aplicação cuidadosa de poder na troca

Tende a incluir algum nível de compartilhamento de benefícios e ônus e ajustes, com o tempo, aos benefícios e ônus, sejam compartilhados ou compartimentalizados 
Trata-se de um construto de extrema utilidade que deve ser visto como um caso especial - uma subcategoria de troca [...]. Em muitos contextos o reconhecimento explícito dos elementos relacionais acrescenta calor, mas não lança luz. (GOLDBERG, 1979, p. 95).

\section{Marketing relacional: 0 casamento de comprador e vendedor}

A troca relacional pode oferecer uma vantagem competitiva na medida em que contribua pra a diferenciação de produto e crie barreiras à mudança (Day e Wensley, 1983). Apesar desse potencial, os vendedores muitas vezes deixam de perceber a necessidade de gerenciar seus relacionamentos com clientes. N otando que a atividade de troca normalmente se intensifica após a venda inicial nos setores de serviços financeiros, consultoria, sistemas de suprimento de manutenção/reparos/operacionais e bens de capital, Levitt (1983, p. 111) declara que "[...] a venda simplesmente serve para a consumação do 'namoro' entre comprador e vendedor. Então tem início o casamento. 0 quanto esse casamento será bom vai depender de como o vendedor administrar o relacionamento".

Embora assimétrica em sua atribuição da responsabilidade pela administração do relacionamento ao vendedor (apenas um dos "cônjuges"), a anal ogia do casamento de Levitt é adequada. De fato, pesquisas que analisam a atração interpessoal e as relações de interdependência entre maridos e esposas fornecem um arcabouço adequado para descrever a evolução dos relacionamentos comprador-vendedor. Como observa McCall,

[...] o casamento é um contrato oneroso restritivo. As duas partes se comprometem mutuamente a efetuar trocas apenas uma com a outra, pelo menos até que 0 saldo das trocas se torne desfavorável em termos da conjuntura mais ampla do mercado. (MCCALL, 1966, p. 197-198).

$\mathrm{N}$ a relação marido-esposa, os benefícios da companhia, da procriação, da criação de filhos, do crescimento pessoal, do compartilhamento da manutenção do lar e do apoio social estão de um lado da balança. Do outro lado, o casamento costuma limitar as opções sociais e sexuais, trazer maior responsabilidade, exigir cuidado e nutrição, e pode envolver uma dissolução dispendiosa.

As relações comprador-vendedor envolvem benefícios e custos análogos. Dentre os primeiros estão menor incerteza, dependência administrada (Spekman,
Strauss e Smith, 1985), eficiência de troca e satisfação social derivada da associação. A cima de tudo está a possibilidade de ganhos significativos das decisões conjuntas e, conseqüentemente, também das individuais, por causa da comunicação eficaz e da colaboração para a consecução de metas. A percepção do comprador quanto à eficácia da relação de troca, portanto, representa uma barreira significativa à mudança e, para o vendedor, uma vantagem competitiva que o isola da competição em preços.

É possível, contudo, que os custos efetivos ou previstos superem os benefícios da troca relacional. A manutenção da associação exige recursos. Partes que estejam sujeitas a metas altamente divergentes podem despender recursos econômicos e psíquicos consideráveis nos processos de conflito e barganha. Ainda maiores podem ser os custos de oportunidade de trocas prévias com parceiros alternativos. Um fabricante de titânio que atrele $25 \%$ da capacidade do ano seguinte a uma margem de $20 \%$ pode impedir a si mesmo de obter outra grande encomenda à margem de $25 \%$. Alternativamente, um consumidor que abra uma conta corrente e peça apenas uma pequena quantidade de cheques pode estar fazendo um hedge contra a possibilidade de que surja a oportunidade de abrir conta em outro banco com menores tarifas ou serviços ampliados.

Jackson (1985) dedicou especial atenção a situações de marketing industrial como o exemplo acima, em que o comprador incorre em elevados custos de mudança. A autora concentrou-se nos custos de mudança mais ligados às características tecnológicas e de utilização de produtos (como computadores e sistemas de comunicação, que exigem serviços constantes ou expansão técnica) do que ao nível de desempenho do parceiro de troca. Entre outros fatores, indicamos que a expectativa de el evado custo de mudança por parte do comprador dá origem ao interesse do próprio comprador em manter um relacionamento de qualidade.

A Figura 1 avança no delineamento do universo de possibilidades de motivações diádicas da troca relacional. Enquadrados na linguagem da teoria da troca de Thibaut e Kelley (1959), os eixos definem o investimento motivacional que cada parte faz em (ou os benefícios que cada parte espera de) um relacionamento. 0 modelo foi desenvolvido recentemente, com considerável detalhamento na análise das relações entre membros de canais de marketing (Anderson e $\mathrm{N}$ arus, 1984). Thibaut e Kelley imaginam que uma parte avalie os custos e recompensas gerais da associação total em relação ao nível de resultados disponíveis a partir 
de al ternativas externas à associação. Os autores usam os termos "nível de comparação" (NC) e "nível de comparação das alternativas" ( $\mathrm{NC}_{\text {alt }}$ ), respectivamente, para representar as duas bases de avaliação de resultados de relacionamentos. Por exemplo, para alguém que tenha um ingresso para a temporada do M etro Theater, o NC inclui a certeza de assento prioritário para todas as peças, possivel mente um desconto em relação ao preço do ingresso individual, um processo de compra eficiente, mais uma possível identificação aprofundada com o teatro e o conseqüente prestígio perante a "comunidade artística". O NC do vendedor abrangea receita confiável e certa do ingresso gerada pela venda e especialmente pela renovação de ingressos para a temporada.

Ao destacar os investimentos motivacionais mútuos das partes, a Figura 1 revela que a discussão de Levitt (1983) sobre as relações administradas pelo vendedor abrange apenas uma das muitas formas de troca. Isso não deve depor contra a importância das trocas relacionais administradas pelo vendedor. Pelo contrário, ao lançar luz sobre situações de relacionamentos sustentados pelo comprador e de manutenção bilate- ral de relacionamentos, a Figura 1 aponta os papéis contingentes do vendedor. A Toyota compartilha seus cronogramas de produção com os fornecedores, e consolidou cuidadosamente seu complexo industrial de Toyota City. Da mesma forma, a NASA e o proprietário de uma casa exemplificam as trocas administradas pelo comprador ao orquestrarem o desempenho de seus contratados na montagem de um foguete e numa grande reforma, respectivamente. Além disso, a manutenção bilateral de relacionamentos parece ser a essência daquilo que Shapiro (1985) chama de "parceria estratégica" entre comprador e vendedor, e que é ilustrado pelas joint ventures industriais.

Finalmente, a Figura 1 permite transações desprovidas de elementos relacionais significativos. Nesses casos, para uma ou ambas as partes, NC e NC ${ }_{\text {alt }}$ são aproximadamente iguais. A troca ainda pode ocorrer, mas quando 0 acesso de uma parte às alternativas $\left(\mathrm{NC}_{\mathrm{alt}}\right.$ ) é superior ao da outra, surge uma dentre duas situações possíveis de poder assimétrico (cf. Dwyer e Walker, 1981). E, para completar, retratamos o universo "sem troca". Concessão ou indução al guma que

Figura 1 - 0 universo hipotético dos relacionamentos comprador-vendedor.

Investimento motivacional do vendedor no relacionamento

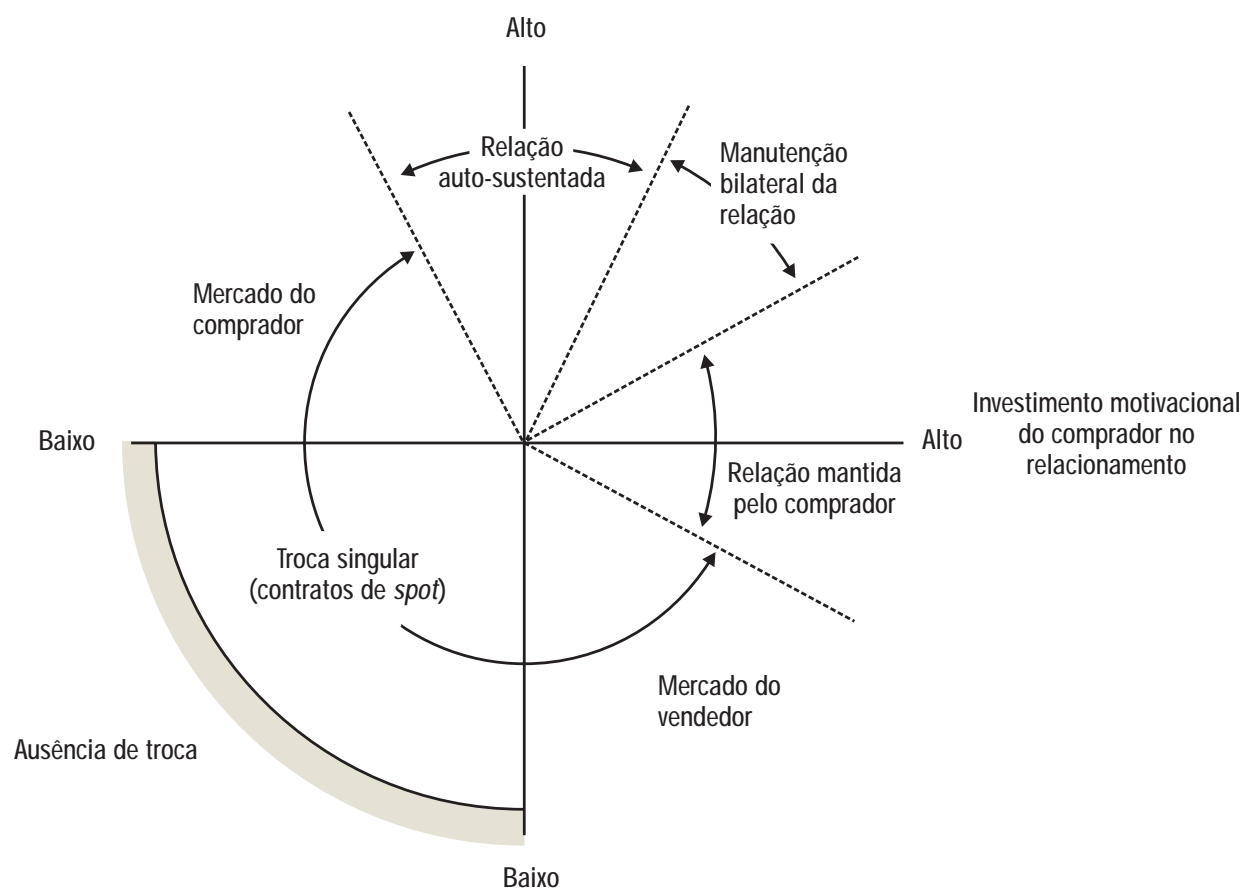


uma parte esteja disposta a oferecer representa satisfação suficiente à outra que motive a troca (Alderson, 1965, p. 84).

Como mapa das possibilidades de troca, a Figura 1 é uma boa representação topográfica. Mas não é um mapa rodoviário, já que oferece poucos detal hes sobre as rotas que levam ao quadrante nordeste. Evidentemente, inúmeros custos e ben efícios das relações comprador-vendedor não podem ser avaliados a priori. Retomando a analogia do casamento, precisamos considerar como transações praticamente singulares (encontros descompromissados) podem evoluir para associações mais duráveis sustentadas por metas, planejamento e compromisso compartilhados.

\section{O PROCESSO DE DESENVOLVIMENTO DO RELACIONAMENTO}

Os relacionamentos se desenvolvem por meio de cinco fases gerais, identificadas como (1) conscientização, (2) exploração, (3) expansão, (4) compromisso e (5) dissolução (cf. Scanzoni, 1979). Cada fase representa uma grande transição em relação à maneira como as partes se percebem.

\section{Fase I. Conscientização}

A conscientização se refere ao reconhecimento, pela parte $A$, de que a parte $B$ representa um parceiro de troca viável. A proximidade situacional entre as partes facilita a conscientização. Assim como é mais provável que uma família conheça melhor seus vizinhos imediatos do que aqueles que moram na rua de baixo, os compradores tendem a estar mais conscientes dos comerciantes e das marcas locais anunciados em meios freqüentemente visual izados.

A interação entre as partes ainda não se deu na fase 1. Embora uma parte possa "se posicionar" e "posar" para se tornar mais atraente para uma outra específica ou genérica, esses atos são unilaterais. Qualquer tipo de interação bilateral, até mesmo a coordenação tácita (Schelling, 1960), marca o início da fase seguinte do desenvolvimento de um possível relacionamento.

\section{Fase II. Exploração}

A exploração se refere à fase de busca e teste da troca relacional. N essa fase, os potenciais parceiros de troca avaliam primeiramente as obrigações, os benefícios e os encargos, e a possibilidade de troca. As compras em clima de experiência têm lugar. A fase de explora- ção pode ser muito breve, ou pode incluir um período prolongado de teste e avaliação. $\mathrm{O}$ vendedor $\mathrm{V}$ pode atender ao comprador $\mathrm{C}$ por meio de promoções e colocação na loja. C pode dar atenção aos anúncios de $\mathrm{V}$ e parar em frente à sua vitrine. Essa avaliação pode resultar numa compra como teste, mas a relação exploratória é muito frágil no sentido de que investimento e interdependência mínimos significam encerramento simples. A fase de exploração é conceitual izada em cinco subprocessos (cf. Scanzoni, 1979): (1) atração, (2) comunicação e barganha, (3) desenvolvimento e exercício de poder, (4) desenvolvimento de normas, e (5) desenvolvimento de expectativas.

Atração. A atração é o processo iniciador da fase exploratória. Ocorre na medida em que o comprador e o vendedor atingem - em sua interação um com o outro - um resultado de custo-benefício superior a um determinado nível mínimo ( $\mathrm{NC}_{\text {alt }}$ ) (Secord e Backman, 1974). As recompensas decorrem das gratificações tangíveis e intangíveis proporcionadas pela associação; os custos incluem impedimentos econômicos (dinheiro, inconveniências) ou sociais.

A literatura sobre atração interpessoal dedicou especial atenção às recompensas. Estas podem estar assentadas em uma semelhança percebida de crenças, valores ou personalidades. Além disso, recursos complementares, como dinheiro, informação, serviços, legitimidade e status, encorajam uma percepção favorável dos benefícios e ônus. Reconhecendo fontes de recompensa tanto contingentes quanto não contingentes (John, 1984; Lusch e Brown, 1982), Lott e Lott (1974) catalogam diversos tipos de recompensa que podem gerar atração.

- Recompensas diretamente proporcionadas pelo outro, como:

- pagamento pelo cliente

- o produto do vendedor fornece benefícios funcionais

- Características do outro como fonte de recompensa, como:

- o sucesso da alma mater nos esportes gera orgulho nos ex-alunos

- "fomos os primeiros [...] McDonnell Douglas"

- "patrocinador oficial da Olimpíada de 1984"

- Similaridade da atitude do outro como reforço da própria competência, como:

- representante de vendas constrói elos de identidade com o cliente prospectivo 
Comunicação e barganha. Define-se barganha como o processo pelo qual, frente à resistência, as partes reorganizam suas distribuições mútuas de obrigações, benefícios e ônus. A disposição percebida para negociar pode ser um aspecto significativo da atração que, por si só, sinaliza que o parceiro de troca em potencial percebe possível valor numa relação de troca. Há conseqüências relacionais surpreendentes quando as partes passam a efetivamente barganhar.

Um indicador significativo do desenvolvimento ou a mudança progressiva em qualquer associação se encontra no ponto em que os parceiros percebem que as recompensas em potencial são suficientemente grandes para se darem ao trabalho, e despenderem as energias psíquicas e físicas necessárias, de negociar. (SCANZONI, 1979, p. 72).

$N$ as rel ações em desenvolvimento, há freqüentemente al guma relutância em dar início à barganha. No começo, as partes fazem rodeios, sugerindo suas preferências ou declarando-as incidentalmente, ao mesmo tempo em que demonstram interesse nas metas umas das outras (Leigh e Rethans, 1984; Pruitt, 1981). Por meio de perguntas e respostas, compradores e vendedores desenvolvem um processo em rodadas, facilitando a interação (Knapp, 1978; LaFrance e Mayo, 1978). Para conhecer muito bem um ao outro, podem tentar revelar informações específicas a seu próprio respeito, suas necessidades ou seus recursos. Para que a relação sobreviva a esse estágio, é preciso que a divulgação de dados íntimos seja recíproca (Cozby, 1973; David e Skinner, 1974). Mais adiante, quando as partes estiverem ambas projetando sua associação em direção ao futuro, pode haver menor necessidade de reciprocidade tão rígida, já que o futuro promete oportunidades e expectativas de equilíbrio.

Então, arriscamos diluir a discutida importância da barganha e da comunicação no desenvolvimento de um relacionamento. Observamos que os comportamentos descritos, embora típicos nas trocas entre empresas, parecem característicos de apenas parte das transações com consumidores, aquelas que envolvem bens duráveis de al to preço e serviços complexos (cf. Dwyer 1984, p. 680). Superficialmente, os preços administrados e o merchandising de massa de itens de baixo preço parecem excluir a possibilidade de barganha explícita. Enfatizamos, contudo, que a incerteza da troca e aquilo que nela está em jogo têm efeitos importantes sobre a medida e a natureza da barganha. Ou seja, um consu- midor pode negociar explicitamente um desconto por grande volume de donuts ao montar uma recepção para o café-da-manhã após um culto religioso ("jogo" al to). A venda de um único pão ("jogo" baixo) provavelmente não envolverá barganha, a menos que o padeiro tente vender pão de um tipo desconhecido (incerteza), se o tipo favorito do consumidor estiver em falta.

Há evidentes eficiências de venda a serem extraídas da administração dos preços. Além disso, os preços administrados são úteis para gerenciar as aspirações de milhões de consumidores atreladas à "postura" de barganha do vendedor (veja Raiffa, 1982, p. 13). Assim, e por bons motivos, a comunicação não chega a ser completa nesse ambiente. A barganha e os esforços de coordenação são predominantemente tácitos (Alderson, 1957, p. 130; Schelling, 1960). Os vendedores interagem com "representantes" do mercado quando usam focus groups [grupos específicos] e pesquisas de opinião. Além disso, adiamento de compras, acúmulo e outros são como formas sutis de barganha tácita por bens de consumo de baixo preço, com conseqüências surpreendentes quando se consideram miIhões de domicílios. Os raros casos de barganha explícita, como sugestões, reclamações e pedidos de compensação, deveriam ocupar um lugar de destaque na atenção dos vendedores porque refletem metas e prioridades do consumidor e um envolvimento relacional com a marca ou loja.

Final mente, enfatizamos que a negociação em si não leva a um relacionamento duradouro. É possível que a barganha ocorra numa transação praticamente singular, como uma venda em processo de inventário ou num mercado de coisas usadas ou penhoradas. N esses casos, nenhuma das partes espera ter um relacionamento com a outra no futuro (Weitz, 1981), e o estilo e o tom de suas estratégias de negociação são reflexo desse fato (Raiffa, 1982).

Propomos, assim, que, embora seja possível que compradores e vendedores barganhem os termos daquilo que essencialmente representa um contrato singular, parece improvável que se forme um relacionamento sem comunicação bilateral de desejos, problemas, insumos e prioridades. $N$ a medida em que as partes em si mudam com o passar do tempo e seus respectivos ambientes exercem demandas variáveis, é inevitável que a valoração dos resultados da associação comprador-vendedor flutue. Ao buscar ou conceder acomodação numa associação de troca atual, em vez de em outra nova, o comprador e o vendedor confirmam seu investimento mútuo no relacionamento. 
Poder e justiça. Embora se separem os processos correlatos de barganha e poder para fins de discussão, eles na realidade continuam inseparáveis. Com maior tradição na área de marketing do que a barganha, 0 poder é tido com a capacidade de atingir os efeitos ou metas pretendidos (Dahl, 1957). O poder da parte A sobre a parte $B$ é determinado pelo grau de dependência de $B$ com relação a $A$ para ter acesso a recursos que Ihe são valiosos (Emerson, 1962; Thibaut e Kelley, 1959). Assim, fazem-se e obtêm-se concessões em decorrência do poder exercido numa barganha.

Os recursos mediados por A dos quais B seja dependente podem assumir muitas formas (cf.. French e Raven, 1959), mas, para os fins deste estudo, é útil conceber sua aplicação como sanções "justas" ou "injustas". 0 exercício de uma fonte de poder injusta controlaria ou influenciaria os atos de B para promover as metas de $A$ sem o consentimento de $B$, contra a sua vontade ou sem a sua compreensão (Buckley, 1967; Raven e Kruglanski, 1970). O exercício de uma fonte de poder justa, por outro lado, implica atendimento e comportamentos voluntários para a consecução de metas coletivas. ${ }^{1}$ Assim, quando A tenta dominar ou coagir B para que apresente determinado comportamento sem oferecer recompensa suficiente, direta ou indireta (Lusch e Brown, 1982) para que B perceba tal atendimento como al go que vale a pena, B pode optar por encerrar a associação. Havendo interdependência mínima nesse estágio, o rompimento é bastante fácil. $\mathrm{Se}$, contudo, o exercício de poder de A for considerado "justo" e B atender, a associação passa de um tipo "em que os interesses individualistas preponderam para outra em que os interesses conjuntos crescem em importância" (Scanzoni 1979, p. 75). Com efeito, o exercício bem-sucedido de poder pode ser uma distinção crucial entre as fases de exploração e expansão. Os exemplos a seguir esclarecem o ponto.

À medida que a desregulamentação acirrou a competição em serviços financeiros no início da década de 1980, muitos bancos aumentaram seus esforços para segmentar mercados e segregar custos operacionais. 0 resultado foi uma variedade de abordagens usadas para incentivar os depositantes a usar caixas el etrônicos em vez de ir aos caixas. Alguns bancos impuseram tarifas de $\$ 1$ para retiradas junto ao caixa humano de contas pequenas. Outros deram ênfase à educação e incentivaram com prêmios o uso de caixas eletrônicos. Aplicando o arcabouço de desenvolvimento de relacionamentos, seria de se prever que a primeira abordagem apresentasse baixa retenção de contas. In- dependentemente de qual explicação das realidades econômicas se use para dar sustentação ao programa, seu aspecto coercitivo e auto-indulgente põe em cheque sua legitimidade. Por outro lado, a abordagem por meio de educação/recompensa se volta para metas compartilhadas e expande a interdependência das partes, já que o banco adquire um segmento de mercado mais lucrativo e os correntistas fazem um investimento específico ao aprender a usar os caixas eletrônicos.

Desenvol vimento de nor mas. As normas e padrões de conduta que caracterizam um contrato relacional tomam forma na fase exploratória do desenvolvimento do relacionamento. As normas oferecem "orientação para as sondagens iniciais que parceiros de troca em potencial podem realizar entre si" (Scanzoni, 1979, p. 68). As normas são "padrões esperados de comportamento" (Lipset, 1975, p. 173). Ao adotarem normas e estabelecerem padrões de comportamento, os parceiros de troca emergentes começam a estabelecer as regras das trocas vindouras.

Os conceitos de normas que existem "antes da troca social e são para ela trazidas" (Ekeh, 1974, p. 45) são ilustrados no trabal ho teórico de Leigh e Rethans (1984). Mais de 40\% dos agentes compradores de sua amostra descreveram as seguintes atividades esperadas num "processo de negociação pós-cotação": (1) chegada do vendedor ao escritório do agente comprador, (2) troca de saudações/bate-papo, (3) o comprador abre negociações sobre o preço, (4) o vendedor reage, [...] (7) troca de comentários no encerramento. Expectativas generalizadas como essas orientam as percepções de troca social e exercem forte influência sobre o comportamento.

Uma vez que as partes tenham se reunido e começado a trocar recompensas, el as freqüentemente estabelecem normas que não existiam antes da interação. Assim, o "consenso espontâneo" (Fox, 1974) pode dar sustentação à troca inicial entre o cliente e seu barbeiro, mas, ao mesmo tempo, a experiência moldará as expectativas quanto à próxima transação (Brickman, 1974). Em forte harmonia com nosso conceito de poder "justo", Fox (1974, p. 86) indica que as pessoas "que compartilham metas comuns são capazes de al ocar papéis entre si à luz do que percebem como 'necessidades funcionais'".

Desenvolvimento de expectativas. As expectativas relacionais se referem aos conflitos de interesses e aos prospectos de união e dificuldades. Essas expectativas podem aumentar ou diminuir a solidariedade contratual. Confiança é um conceito importante para com- 
preender as expectativas quanto à cooperação e ao planejamento num contrato relacional. Golembiewski e M cC onkie (1975, p. 131) vão al ém, sugerindo que "talvez não haja nenhuma outra variável que, por si só, tenha tanta influência sobre o comportamento interpessoal e intergrupal". A confiança é um conceito que apenas recentemente se tornou foco da pesquisa sobre a interação comprador-vendedor. Schurr e Ozanne (1985, p. 940) baseiam-se em Blau (1964) e Rotter (1967) para definir a confiança como "a crença de que a palavra ou a promessa de uma parte seja confiável e cumprirá com suas obrigações num relacionamento de troca". Numa simulação de compras industriais, Schurr e Ozanne revelaram que as expectativas dos compradores quanto à segurança e à atitude de barganha afetam significativamente suas atitudes e seus comportamentos frente ao fornecedor atual. Um baixo nível de confiança estimula atitudes, comunicação e comportamento de barganha menos favoráveis em relação ao fornecedor atual.

Pruitt (1981, p. 101) acredita haver uma relação próxima entre a confiança e o desejo de coordenar com outra parte. Ele sugere que uma parte que deseje se coordenar com outra de sua confiança tende a apresentar comportamentos coordenativos de el evado risco. Alguns exemplos de ações de alto risco são: (1) uma grande concessão em busca de reciprocidade, (2) uma proposta de chegar a um meio-termo, (3) uma ação unilateral redutora de tensões e (4) declarações francas a respeito das próprias motivações e prioridades.

Entre os exemplos de medidas sustentadas para angariar confiança estão a manutenção de uma boa qualidade de crédito por parte dos compradores e o uso, pel os vendedores, de estímulos implícitos à confiança como marcas de fantasia, marcas registradas e logomarcas, e garantias explícitas (Schurr e Ozanne, 1985). M as a experiência direta tende a ser a principal base para o julgamento do nível de confiança durante a fase exploratória. É uma faceta crucial do arcabouço conceitual de Swan (Swan e Nolan, 1985; Swan, Trawick e Silva, 1985) para o desenvolvimento, pelo vendedor, da confiança depositada pelo cliente.

Em suma, os cinco subprocessos são aspectos importantes da fase exploratória porque permitem, a cada uma das partes, avaliar e testar a compatibilidade de metas, e a integridade e o desempenho da outra.

\section{Fase III. Expansão}

A expansão se refere ao aumento contínuo dos benefícios obtidos pelos parceiros de troca e à sua crescente interdependência. Os cinco subprocessos apresentados na fase exploratória também agem na de expansão. A distinção crítica está no fato de que os fundamentos da confiança e satisfação conjunta estabel ecidas na fase exploratória levam, agora, a díade a assumir maiores riscos. Conseqüentemente, aumentam a amplitude e a profundidade da dependência mútua. “[A] associação desenvolveu-se ou evoluiu significativamente em relação àquela caracterizada por sondagem, testes, exames, etc., passando a se caracterizar por uma ampliação contínua dos tipos de recompensa que os parceiros oferecem um ao outro e, assim, de sua interdependência" (Scanzoni, 1979, p. 791).

Frazier (1983a, 1983b) apresentou o processo de expansão como conseqüência da satisfação de cada parte com o desempenho da outra e com as recompensas a ela associadas. O u seja, os resultados das trocas na fase exploratória representam um teste da capacidade e da disposição da outra para dar satisfação (Blau, 1964). Quando uma parte cumpre exemplarmente suas obrigações percebidas de troca, o grau de atração que exerce sobre a outra aumenta (Thibaut e Kelley, 1959). Assim, aumenta a motivação para manter o relacionamento, especialmente porque resultados de alto nível reduzem o número de alternativas que um parceiro de troca poderia usar como substitutos (Frazier, 1983b, p. 159). As percepções resultantes de congruência de metas e cooperação levam a mais interações, além daquelas estritamente necessárias no início.

As estratégias de crescimento intensivo de penetração no mercado e desenvolvimento de produto (Ansoff, 1957) dependem do processo de expansão. Por exemplo, o Citibank usou anúncios em jornais e mala direta junto a clientes de crédito para promover um produto inovador de segunda hipoteca em Baltimore. 0 programa aumentou a presença de mercado do banco numa área tradicionalmente fraca e, o que é mais importante, permitiu que ele usasse o processo para upselling. Ou seja, os solicitantes aumentaram o montante de seus empréstimos e compraram outros serviços financeiros após conversar com um gerente de agência do Citibank (Advertising Age, 1986). Numa expansão semelhante gerenciada pelo comprador, a Procter \& Gamble aprofundou seu relacionamento com uma distribuidora de telemarketing para (1) vender fraldas aos pais de bebês prematuros, (2) atender a adultos com incontinência e (3) mais recentemente, identificar tomadores de decisão de contas consideradas para venda de óleo comestível no mercado institucional. 


\section{Fase IV. Compromisso}

O compromisso se refere a uma declaração implícita ou explícita de continuidade relacional entre os parceiros de troca. N esta fase, a mais avançada da interdependência comprador-vendedor, os parceiros de troca atingiram um nível de satisfação a partir do processo de troca que virtualmente exclui outros parceiros que possam fornecer benefícios semelhantes. Os participantes não deixaram de verificar al ternativas, mas se mantêm cientes delas sem "testes constantes e frenéticos" (Scanzoni, 1979, p. 87). Atingiu-se a fidelidade do cliente (vendedor).

Normalmente, o conceito de compromisso traz as conotações de solidariedade e coesão, mas esses sinônimos são vagos. Precisamos considerar três critérios mensu ráveis de compromisso (Scanzoni, 1979): insumos, durabilidade e consistência.

Insumos. 0 primeiro critério de compromisso está em fornecerem as partes níveis relativamente elevados de insumos para a associação (Blau, 1964). Podem ser trocados recursos econômicos, comunicativos e/ou emocionais significativos.

Durabilidade. Em segundo lugar, a associação precisa demonstrar durabilidade. Segundo Macneil (1980, p. 95), "a solidariedade orgânica consiste numa crença comum na eficácia das trocas futuras".

Uma relação duradoura em si pode ou não ter estabilidade de conteúdo, dependendo dos ajustes ambientais necessários e da disposição dos participantes para fazer tais ajustes (Scanzoni, 1979). A durabilidade presume que as partes sejam capazes de discernir os benefícios que podem ser atribuídos à relação de troca e antever um ambiente que permita que as trocas eficazes perdurem. Dadas tais expectativas, as partes podem vincular-se a ponto de encorajar investimento contínuo na relação. Williamson (1983) argumenta, nesse sentido, que a troca de "reféns" (troca bilateral de ativos humanos ou físicos específicos da transação) comunica credibilidade do compromisso para com o relacionamento e, portanto, apóia maiores alianças e trocas. 0 problema principal da franquia ilustra esse ponto:

Os franqueados investem nos estoques, nos sinais e na promoção do franqueador. 0 franqueador treina seus distribuidores e fornece conhecimento especializado sobre técnicas do negócio. Parte al guma incorreria em tais custos sem pelo menos al guma expectativa de que 0 relacionamento perdure por tempo suficiente que permita recuperar os gastos. (GOLDBERG, 1979, p. 99).
As expectativas de continuidade do franqueado derivam de taxas de franquia não reembolsáveis, cláusulas restritivas à concorrência e custos previstos de mudança de locais de propriedade do franqueador. Os royalties baseados numa porcentagem do faturamento bruto refletem uma fórmula de compartilhamento que faz com que o distrato em mercados "quentes" seja menos atraente para o franqueador do que uma taxa fixa por todos os serviços prestados ao franqueado. Em mercados de consumo, investimentos semel hantes são evidentes nos depósitos de caução, abatimentos tardios, créditos acumulados por compras e assemel hados.

Consistência. 0 terceiro aspecto do compromisso é a consistência com que são fornecidos insumos para a associação. Em termos de expectativa, quando os níveis de insumo de uma parte flutuam, a outra terá dificuldade para prever os resultados da troca. A inconsistência da primeira reflete baixo compromisso e leva a uma redução da confiança da outra em relação aos resultados da troca. Uma distinção fundamental da fase de compromisso é o fato de que as partes dedicam intencionalmente recursos à manutenção do relacionamento. De fato, Levinger e Snoek (1972) empregam a seguinte analogia: assim como as ligações físico-químicas tendem à entropia, as ligações sociais tendem a se enfraquecer e se dissolver a não ser que recebam manutenção ativa.

Muitas forças podem desgastar um relacionamento, inclusive custos crescentes de transação, menores obstáculos associados à interação com um parceiro de troca alternativo e uma mudança das necessidades pessoais ou organizacionais, levando a uma pior valoração das recompensas. Por outro lado, a pressão para ajustar um relacionamento em vez de dissolvê-lo é alimentada pelos benefícios contínuos que percebe cada parte. Esses benefícios incluem a certeza de papéis e metas mutuamente antevistos, a eficiência que decorre do aprimoramento do papel ou da barganha ( McCall e Simmons, 1966) e a garantia de eficácia de troca que decorre da confiança.

\section{Fase V. Dissolução}

A possibilidade de retirada ou distrato esteve implícita em todo o nosso arcabouço do desenvolvimento de relacionamentos. Ou seja, nem todo elo diádico de que o comprador ou o vendedor esteja ciente entra na fase exploratória, e nem toda relação sondada e testada durante a exploração se expande ou vem a se solidificar pel o compromisso. A té aqui, apenas nos baseamos no cál culo da teoria das trocas (Emerson, 1962; Raven 
e Kruglanski, 1970; Thicbaut e Kelley, 1959; veja a Figura 1) para explicar o rompimento. Esse modelo representa uma ótima perspectiva analítica, mas deixa inexplicado o processo da dissolução.

Esses processos são de grande conseqüência quando se dão após as partes terem atingido a elevada interdependência características das fases de expansão e compromisso. 0 encerramento de relacionamentos pessoais é uma fonte significativa de desgaste psicológico, emocional e físico (cf. Bloom, Asher e W hite, 1978; Hill, Rubin e Peplau, 1976). Com base em evidências anedotais, a dissolução de relacionamentos comerciais impõe desgastes assemelhados. Considere, por exemplo, o trauma da Coca-Cola ao tentar interromper a produção da "velha" Coca, a custosa saída da Kodak do mercado de fotografia instantânea e o longo processo de litígio antitruste que muitas vezes encerra relacionamentos de canais de distribuição (por exemplo, M onsanto Co. versus Spray-Rite Service Corp. 1984).

Infelizmente pouco se sabe do distrato. Há, provavel mente, diversas traj etórias que levam à dissolução, e corremos o risco de simplificar em demasia se dedicarmos quatro fases ao desenvol vimento do relacionamento e apenas uma à dissolução. Embora alguns estudiosos tenham achado útil conceber a dissolução como o inverso da formação de relacionamentos (cf. Altman e Taylor, 1973; Miller e Parks, 1982), acreditamos ser produtivo abandonar esse raciocínio. A Figura 1 e o nosso arcabouço enfatizam os esforços bilaterais ( o que não equivale a dizer que são necessariamente iguais) de desenvolvimento de um relacionamento. Entretanto, a dissolução pode ser mais facilmente iniciada unilateralmente. Ademais, as evidências acumuladas parecem contradizer a hipótese do caminho reverso.

Grande parte do trabalho empírico foi realizada por Baxter (1979; Baxter e Philpott, 1982), posicionado dentro de um arcabouço conceitual em quatro estágios extraído de Duck (1982). Esse model o sustenta que a dissolução parte de um estágio intrapsíquico em que uma das partes avalia no âmbito privado suas insatisfações com a outra, concluindo que os custos de continuação ou modificação superam os benefícios. Posteriormente, o relacionamento entra numa fase interativa em que as partes negociam sua desvinculação. A dissolução é, então, apresentada publicamente na fase social. Finalmente, o "luto", a recuperação social e psicológica do afastamento, conclui o processo, embora nenhuma das duas partes volte ao seu estado anterior ao relacionamento.
Enfatizando a fase interativa em seus estudos, Baxter (1985) identifica duas dimensões-chave das estratégias de desvinculação: a direta e a voltada para o outro. Estratégias diretas declaram explicitamente à outra parte o desejo de deixar um relacionamento; as indiretas procuram chegar ao rompimento sem declaração explícita dessa meta. "A orientação para o outro capta o quanto o interessado no distrato evita magoar a contraparte no rompimento" (Baxter, 1985, p. 247). As parcimoniosas distinções de Baxter fazem delas um promissor ponto de partida para o exame da dissolução dos relacionamentos comprador-vendedor.

\section{Vantagens e desvantagens do modelo}

Argumentamos que a pesquisa de marketing negligenciou, em grande medida, os elementos relacionais da troca comprador-vendedor. A representação oferecida por Mcneil (1980) de características contrastantes das trocas singulares e relacionais levou à nossa concepção de motivações diádicas para formas alternativas de troca, como na Figura 1. Para tratar de processos interativos capazes de reduzir ou ampliar as motivações mútuas custos e benefícios percebidos da troca sustentada - , propomos um arcabouço do desenvolvimento de relacionamentos.

A Figura 2 é um resumo mínimo do modelo, destacando as transições primárias e as características das fases. A conscientização é um processo unilateral anterior à troca. Considerações mútuas e interações diádicas dão início à fase exploratória, que é basicamente um período de teste do relacionamento. Trocas repetidas podem refletir um período de teste prolongado. A associação para troca é facilmente encerrada nesse estágio. Mas se as partes se comunicarem de forma eficaz, negociando papéis que reflitam insumos "justos" das partes e formando expectativas quanto a futuras interações promissoras, a associação entra na fase de expansão. A fase de compromisso, então, sustenta elevados níveis de dependência mútua, circunscrevendo a relação de troca por meio de estruturas de valor e mecanismos contratuais que garantam sua durabilidade. A desvinculação das fases al tamente interdependentes de expansão e compromisso não é um processo reverso. Pode ser complexa e dispendiosa. É um processo de marketing estratégico pouco compreendido.

Observamos que o modelo se baseia predominantemente em fundações conceituais e evidências empíricas da teoria das trocas e de seus frutos - a teoria do matrimônio, da barganha e do poder. Muito resta a fazer na distinção dos relacionamentos comerciais, 
profissionais e românticos. Além disso, o modelo é apresentado abstratamente. Faltam-Ihe detal hes conceituais e meios óbvios de operacionalizar variáveischave.

N essa forma abstrata, contudo, 0 arcabouço tem suas vantagens. Procuramos oferecer um modelo suficientemente genérico para abranger os relacionamentos tanto entre empresas quanto de consumo. Embora 0 direito contratual moderno pareça dar ênfase aos comportamentos entre empresas, o model o do processo tem suas raízes nos fenômenos interpessoais. A tomada de decisão por múltiplas partes e o maior cacife em jogo distinguem o desenvolvimento de relacionamentos entre empresas do de relacionamentos de consumo, mas fatores semel hantes podem operar em determinadas situações de compra de consumo, e parecem ser facilmente acomodadas pelo arcabouço. Assim, afirmamos que o model o suporta a "Iógica da descoberta" (Hunt, 1983b, p. 21-25), sugerindo idéias e categorias para o agrupamento de fenômenos. Assim como o conceito de centro de compras, o modelo fornece um ar- cabouço para a unificação e ampliação de nosso entendimento. Para ilustrar, oferecemos sugestões de pesquisa e esforços administrativos.

\section{ORIENTAÇÕES DE PESQUISA}

\section{Transições}

Os esforços iniciais de pesquisa devem enfrentar a premissa básica do arcabouço de desenvolvimento de relacionamentos, a expansão gradual da interdependência. Com ênfase histórica sobre as transações como eventos singulares, o marketing fez um significativo avanço na compreensão da transição entre a consciência e a exploração. Esse avanço está bem documentado na revisão e integração de modelos de resposta à informação de Smith e Swinyard (1982). É importante observar que, em seu modelo integrado, esses autores observam o significativo papel da experiência comportamental com o produto na formação de crenças e afeições de alta ordem.

Figura 2 - 0 processo de desenvolvimento do relacionamento.

Fase de relacionamento

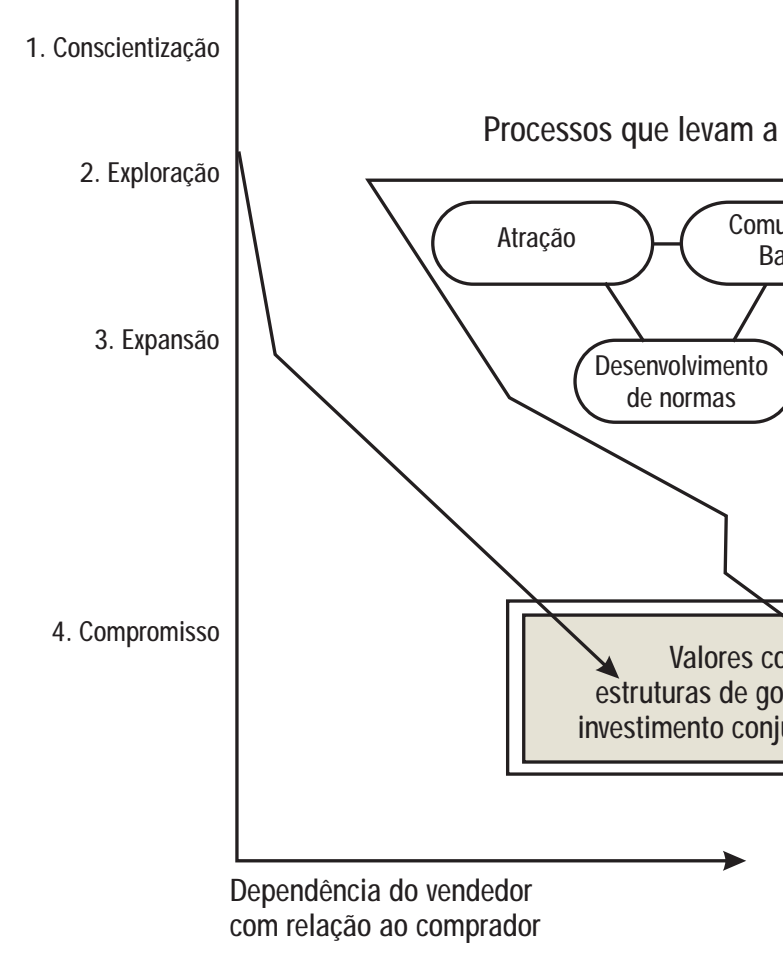

Características da fase

1. Consideração unilateral de parceiros de troca em potencial.

2. Ocorre interação diádica. Um aumento gradual da interdependência reflete os testes e sondagens bilaterais. É simples encerrar a frágil associação.

3. 0 exercício bem-sucedido de uma fonte de poder marca o início da Expansão. A satisfação mútua com a representação dos papéis dá sustentação a um aprofundamento da interdependência. Busca-se maior gratificação a partir do parceiro de troca atual e não de um parceiro alternativo.

4. Mecanismos contratuais e/ ou sistemas de valor compartilhados para garantir interdependência sustentada. Os insumos mútuos são significativos e consistentes. Os parceiros solucionam conflitos e se adaptam. relação ao vendedor 
Mas sabemos relativamente pouco sobre os importantes processos de sondagem e teste da fase de exploração. A plicarão as partes testes heurísticos de hipóteses? Em caso positivo, quais serão as origens de suas expectativas? O que está em "jogo" afeta o "poder" dos testes? Qual a variação do exercício "justo" de poder entre fontes de poder e parceiros de troca?

Se uma relação sobreviver às fases de exploração e expansão, a transição para o compromisso exige altos níveis de congruência entre metas ou mecanismos de aplicação "herméticos" (reféns ou outras sanções). Como o processamento humano de informações é necessariamente imperfeito e se manifesta especialmente em ambientes complexos e incertos, pode ser impossível arquitetar mecanismos intei ramente auto-aplicáveis para dar sustentação às crescentes interdependências do compromisso. Assim, a avaliação do relacionamento nas fases anteriores pode enfatizar a motivação atribuída em detrimento da boa representação de papéis.

Transições negativas, encerramentos ou retrocessos do relacionamento também merecem estudo cuidadoso. Especial mente na fase de compromisso, a metáfora conjugal e as evidências oferecidas por Baxter (1985) nos compelem a ver o distrato como algo mais do que uma inversão do desenvolvimento. 0 desligamento de tão avançado estado de interdependência tende a tornar obsoletos investimentos especificamente voltados à transação ou deixar profundas cicatrizes emocionais que podem bloquear níveis relacionais intermediários. M esmo em acordos bilaterais de "dissolução gradual" ou "pseudoinvolução", as partes "mantêm uma fachada de relacionamento contínuo, ao mesmo tempo em que pretendem ausência total de contato entre si" (Baxter, 1985, p. 248).

A transição da expansão de volta para a fase de exploração podeser menos dramática. 0 retrocesso pode não deixar obsoletos os investimentos no relacionamento, nem deixar cicatrizes profundas. Talvez nenhuma das partes deseje eliminar a possibilidade de maior interdependência futura, embora a atual situação justifique um passo atrás. Evidentemente, quando as partes têm visões diferentes do estado do relacionamento, o distrato pode ser dificultoso. U m distribuidor que tenha construído seu negócio em torno de uma linha específica de equipamentos enxerga os esforços de venda direta do fabricante como uma transição negativa que impede qualquer possibilidade futura de dependência el evada. Enquanto isso, o fabricante pode ter por intenção apenas complementar a rede do distribuidor, prevendo ampliar sua linha de produtos na década seguinte.
Finalmente, é importante observar que um grande número de situações de troca duradoura pode comprimir as fases de exploração e expansão. A categoria de troca "irremediavelmente perdida" [lost-for-good] de Jackson (1985), caracterizada por el evados custos de mudança do comprador, é um bom exemplo. Raciocinando principal mente a partir da economia do custo de transação de Williamson (1975), ela propõe que os fatores que tendem a impelir em direção à interiorização também favorecem trocas relacionais por meio de contratação spot recorrente. Resumindo, esses fatores incluem interações freqüentes, prestações au ditáveis/garantidas e um el evado grau de investimentos duráveis e específicos. Nesses casos, é de se esperar que haja negociações prolongadas entre as partes e dependência relativamente elevada em reputações de confiabilidade, contratos contingenciais e mecanismos de mediação por terceiros.

\section{Negociação}

O segundo item na agenda de pesquisa é o estudo das interações comprador-vendedor como processos de barganha. A negociação representa um excel ente arcabouço de pesquisa sobre a troca rel acional porque suas ricas tradições envolvem importantes condições comunicações e estruturas de poder anteriores que afetam os parceiros de troca, que precisam dividir benefícios e ônus, solucionar conflitos, planejar e exercer poder.

Arndt (1979) ampliou a designação de negociação de Johnston e Bonoma (1977) como responsabilidade fundamental do marketing. A literatura de marketing dedica pouca atenção às negociações, mas há algum avanço (cf. Clopton, 1984; Dwyer, 1984; Schurr e Ozanne, 1985). Esses estudos são de natureza transacional (tática), e ainda há o que fazer para estudar aquilo que Arndt chamou de negociações "contratuais" e "estruturais". As primeiras abrangem os termos de troca durante um período de tempo; as últimas aplicam-se "à forma e à intensidade de rel ações interorganizacionais de longo prazo e profundo comprometimento" (Arndt, 1979, p. 73). Mais uma vez, sugerimos a possibilidade de formas paralelas mais sutis, quiçá tácitas, nas relações de consumo.

O laboratório de negociações pode ser um ponto de partida adequado para o desenvolvimento e a avaliação de medidas de construtos-chave do arcabouço. No contexto do ambiente controlado, as medidas podem ser eficientemente administradas e testadas quanto à sua sensibilidade a manipulações experimentais de dependência, representação de papéis e comunicação. 
Três construtos parecem críticos no atual estágio de nossa compreensão do processo de desenvolvimento do relacionamento: confiança, compromisso e desvinculação.

Confiança. U ma faceta central do desenvolvimento de expectativas, a confiança merece atenção prioritária. Quem talvez melhor resumiu seu papel foi melhor Sullivan e Peterson (1982, p. 30): " [...] quando as partes têm confiança uma na outra, possuem meios de solucionar dificuldades como conflitos de poder, baixa I ucratividade e assim por diante". Oferecemos esse raciocínio em nossa discussão das transições para o compromisso. O u seja, pode ser impossível cobrir todas as contingências num contrato formal de cooperação sustentada, mas se houver confiança entre parceiros, pode ser desnecessário cobrir todas as possibilidades.

Recentes trabalhos sobre confiança e marketing (Schurr e Ozanne, 1985; Swan e Nolan, 1985) apenas arranharam a superfície de suas ricas fundações conceituais e empíricas em pesquisas interpessoais e com pequenos grupos (cf. Worchel, 1979, Zand, 1972). Como medida do resultado da interação diádica, a escala de confiança desenvolvida por Sullivan et al. (1981; Sullivan e Peterson, 1982) demonstrou confiabilidade e validade nomológica. Sua aplicação às relações comprador-vendedor, especialmente as relações entre empresas (confiança como faceta organizacional, não pessoal), merece avaliação atenta.

Finalmente, no arcabouço do desenvolvimento de relacionamentos, a confiança fornece uma posição vantajosa para unificar as tradições de pesquisa sobre poder e conflito no canal de marketing (cf. Gaski, 1984; John, 1984). Grande parte dos trabalhos sobre canais está repleta de referências implícitas à confiança como aspecto do poder de perícia e de recomendação, da cooperação e da confiabilidade de ameaças e promessas. Com efeito, o artigo de John parece crucial ao aliar a preocupação dos economistas institucionais com as falhas do mercado causadas por oportunismo, de um lado, e de outro a preocupação dos psicossociólogos com o desempenho ineficaz de grupos devido à fal ta de cooperação e de risco (confiança). Os primeiros encaram 0 oportunismo como uma característica inerentemente humana que emerge sempre se não for suprimida por estruturas competitivas ou modos de governança adequados à complexidade e à incerteza do ambiente. Os últimos dão ênfase ao aprendizado social como caminho para se chegar à confiança, a uma interdependência ampliada e à eficácia de grupos/sistemas.

Compromisso. 0 compromisso representa o mais elevado estágio de ligação relacional e foi claramente de- finido em termos de três dimensões mensuráveis: insumos, durabilidade e consistência. A parentemente, essas facetas podem ser aplicadas com grande versatilidade ao estudo das relações entre empresas e de consumo. O peracionalizações relativamente auditáveis e rastreáveis fornecem critérios e medidas de situação sistêmica que permitem um estudo detido dos processos do relacionamento, como gerenciamento de conflitos, tomada conjunta de decisões/coordenação e adaptação do sistema. Fornecem ainda sustentação a uma análise comparada de sistemas de poder, segmentos de estilo de vida e tecnologias de produto.

Dissolução. Nossa discussão dos processos de distrato é a mais especulativa. Embora reconheçamos a linha de pesquisa sobre aspectos micro da satisfação/insatisfação do consumidor ( cf. Oliver, 1980), não tem havido estudo sistemático do desacoplamento das partes a partir de relacionamentos altamente evoluídos. Anedoticamente, o chamariz das condenações punitivas triplicadas na arena antitruste parece levar a separações litigiosas entre empresas que, do contrário, poderiam ser evitadas ou solucionadas de forma pacífica por meio de negociação ou arbitragem (Goldberg, 1979). No arcabouço de Baxter (1985), o desenlace antitruste é direto e não voltado para o outro. No sentido oposto, a GM e a Toyota já acertaram o encerramento de sua joint venture envolvendo o automóvel N ova. $\mathrm{O}$ desenlace será direto e voltado para o outro. Será esse um sistema taxonômico útil para avaliar rompimentos com consumidores e entre empresas? Que outras estruturas ambientais incentivam ou desencorajam a dissolução? Mais uma vez, M acneil (1980, 1978) e a metáfora do casamento (Scanzoni, 1982) mostram-se sugestivos.

Trabal hos exploratórios e indutivos que classifiquem muitas dissoluções de relacionamento parecem ser potencialmente úteis para avaliar a eficiência e a eficácia dos processos. Antevemos que as percepções diádicas do processo podem não ser congruentes, e que, frente à resistência, os esforços voltados para o outro de uma das partes, quando da dissolução, podem transformar-se em autodefesa.

\section{Modelos decisórios}

Há diferenças significativas na avaliação administrativa de transações singulares e relacionais. Essencialmente, a avaliação das primeiras parte de um modelo de estímulo-resposta (Arndt, 1979; Johnston e Bonoma, 1977), e a dos últimos, de um modelo de orçamentação de capital (Day e Wensley, 1983). Os custos de aquisi- 
ção de clientes podem ser considerados investimentos contrabalançados pela valoração descontada dos benefícios e ônus ao longo da "vida útil" do cliente (Jackson, 1985). A segmentação do mercado, então, se baseia mais explicitamente em padrões de resposta e outras considerações relacionais. Fiamo-nos no poder de modelos matemáticos avançados para estruturar essa complexidade no marketing de relacionamento.

0 modelo de comportamento do cliente de varejo de Morrison et al. (1982) na Merrill Lynch exemplifica a direção de pesquisa a que nos referimos. M ais especificamente, vemos grande promessa em aprimoramentos a esse modelo, especificamente um algoritmo de agrupamento de clientes, uma matriz de transição ampliada e funções de resposta para diferentes insumos de marketing. Essas últimas modelariam o impacto da programação de marketing sobre as probabilidades de transição dos grupos entre cada fase do desenvolvimento relacional.

\section{APLICAÇÃO DO ARCABOUÇO}

M esmo em sua forma propositiva, o modelo traz duas contribuições à prática administrativa. Primeiro, permite atraentes explicações post hoc para o sucesso ou fracasso de muitas das atuais práticas de marketing. Em segundo lugar, estimula o pensamento em novas direções da programação de marketing.

As breves seções a seguir são mais ricas em afirmação de programas do que em sua geração. Inovações modestas parecem mais alinhadas com o estado embrionário de nosso modelo. Ainda assim, consideramos al tamente promissora a imitação criativa de algumas das práticas de marketing relacional exemplificadas em nossos três grupos de questões administrativas: mensuração do desempenho, gestão do conflito e construção de barreiras à saída.

\section{Mensuração do desempenho}

Em qual quer associação sustentada, cabe às partes avaliar sua satisfação e dar sinais de mudança de prioridades quanto a resultados, exigências do papel e oportunidades de crescimento. Duas táticas administrativas fundamentais oferecem abordagens sensatas. Primeiro, o vendedor pode melhorar os veículos de comunicação emanados a partir dos clientes. Cartões de garantia, demonstrações e exibições, um balcão de atendimento do varejista e concursos que envolvam 0 uso do produto (receitas, por exemplo) são comuns nesse sentido. Canais diretos de comunicação gratuitos e acompanhamento do vendedor são exemplos um pouco mais raros desse aspecto do marketing de relacionamento (Peters e Auston, 1985).

A segunda abordagem é obter, sem incomodar, informações de al ta qualidade sobre as prioridades e a satisfação do cliente no contexto da associação de troca. Para bem realizar o marketing de relacionamento, o vendedor precisa saber se as compras estão aumentando ou diminuindo, se estão se expandindo ou contraindo. Ademais, na medida do possível, o vendedor vai querer antever as mudanças de estilo de vida, ou de ênfase empresarial, de cada cliente, e os conseqüentes deslocamentos para novos produtos e serviços. Bases de dados de baixo custo estão viabilizando acompanhar discretamente uma parcela crescente desses comportamentos, seja no nível industrial, seja no domiciliar. Pedidos de descontos, resgates de cupons, compras com cartão de crédito e dados de inscrição são táticas potencialmente ricas para o marketing de relacionamento. Quando esses dados se combinam com outras bases (por exemplo, Simmons e Prizm) de mídia e perfis de estilo de vida, descortina-se um novo grau de intimidade comprador-vendedor. Tais sistemas oferecem maior eficiência em marketing a partir do agrupamento de contas e do direcionamento de programas, além de maior e melhor atendimento e satisfação do cliente. A AT\& T adotou essa abordagem para direcionar novos programas de pacotes de serviços de longa distância e oportunidades de inserção em rede para proprietários de computadores pessoais. Por outro lado, um vendedor de bens de consumo codificou e armazenou a correspondência de 8 milhões de usuários da marca, mas não iniciou nenhum esforço de marketing relacional baseado em análise ou acompanhamento desde a resposta inicial a cada carta.

\section{Gestão de conflito}

Nosso modelo de desenvolvimento de relacionamentos destaca um processo de interdependência crescente entre comprador e vendedor. Com efeito, as gratificações que cada parte extrai do desempenho da outra e a crescente confiança nas expectativas quanto aos papéis prendem as partes numa rede de interdependências. 0 conflito, divergência entre as preferências quanto a metas e papéis, é previsível no contexto de um relacionamento, assim como são inevitáveis períodos de escassez de recursos, erros de interpretação e mudança de valores ou de conceitos de fair play (cf. Stern e Gorman, 1969; Thomas, 1976). 
Nossa segunda preocupação administrativa, o papel construtivo do conflito comprador-vendedor, refere-se ao dever administrativo de mensurar o desempenho. As conseqüências destrutivas do conflito parecem estar bem documentadas: hostilidade, amargura, greves, violência, polarização de terceiros e isolacionismo. Mas a supressão total do conflito significa que um relacionamento perdeu sua vitalidade ou que as partes estão se separando antes de explorar plenamente a promessa de sua associação contínua (Hirshman, 1970). Enfatizamos aqui os supostos benefícios funcionais do conflito (cf. Assael, 1969; Rosenberg, 1974), entre os quais (1) uma comunicação mais freqüente e eficaz entre as partes e o estabel ecimento de meios para a expressão de insatisfações, (2) uma revisão crítica de atos passados, (3) uma distribuição mais eqüitativa dos recursos do sistema, (4) uma distribuição de poder mais equilibrada na relação, e (5) padronização dos modos de solução de conflitos.

Essas idéias nada têm de pioneiras, mas 0 atual estado de coisas não parece resultar em todo esse espectro de benefícios. Uma pesquisa nacional revelou que a maioria dos clientes insatisfeitos que pediu a ajuda de órgãos governamentais fez tentativas infrutíferas de obter satisfação junto ao vendedor ( Harris e Associados, 1977). Em parte, essas tentativas fracassam porque os compradores e ven ded ores têm normas de acerto incongruentes (Dwyer e Dornoff, 1981). 0 marketing de relacionamento exige o estabelecimento de normas mutuamente aceitas.

Ademais, Weick (1979) sugeriu que o departamento de atendimento ao cliente de al gumas organizações evoluiu de maneira a constituir principal mente um amortecedor cuja função é isolar a administração das más notícias vindas dos clientes. Por outro lado, a possibilidade de preservar e aprofundar o relacionamento por meio de procedimentos e resultados íntegros para reclamações deve alimentar significativas atividades de gestão de conflito. Rastreando a lucratividade de clientes cujas reclamações foram rapidamente solucionadas e comparando-a com a de clientes que nunca apresentaram reclamação, a Omaha Steaks, uma fornecedora de carnes nobres pelo correio, descobriu que os primeiros são mais lucrativos (Kesler, 1985). Assim, o acesso dos clientes a procedimentos padronizados que reflitam uma consideração informada a normas de atendimento a reclamações merece a mais alta prioridade.

\section{Barreiras de saída}

0 marketing de relacionamento exige uma estrutura de troca que não torne atraente o fim do relacionamento. 0 fornecimento consistente de ben efícios econômicos e psicossociais a cada transação é crítico, mas, como motivação adicional para que as partes solucionem conflitos de maneira a manter o relacionamento, pode ser útil criar desincentivos estruturais à dissolução relacional.

As barreiras de saída parecem mais raras nos mercados de consumo do que nos industriais e organizacionais. Ainda assim, é importante reconhecer a presença de barreiras de saída nas relações com consumidores e sua utilidade estratégica. Vejamos al guns exemplos.

- Os programas de milhagem mantêm com eficácia os elos relacionais quando outorgam "milhas de bonificação" proporcionais ao número de linhas alternativas par cada destino.

- Abatimentos tardios dão sustentação a trocas constantes, como, por exemplo, provas acumuladas de selos de compras usados como moeda no catálogo de brindes do fabricante.

- Cauções pagas em contratos de locação são garantias de cumprimento do contrato.

- O "investimento" de um consumidor em bens duráveis o prende à compra freqüente de suprimentos consumíveis específicos.

Acreditamos haver outras oportunidades de implementação e ajuste fino dessas práticas. M ais especificamente, há promessas de recompensa de status ou reconhecimento social pela longevidade do relacionamento. Como o Gallon Donor da campanha de marketing de doação de sangue ou o Consel ho do Presidente no levantamento de doações de campanha, pode haver valor no reconhecimento de quem assine a revista Time por 5, 10 e 25 anos, ou compre três Buicks seguidos. Por outro lado, a dissolução é encorajada pelos clubes de discos que recompensam o encerramento (e não a lealdade) por meio de atraentes ofertas de (re)inscrição.

\section{CONCLUSÃO}

Encorajados pelos contrastes entre trocas singulares e relacionais segundo Arndt (1979) e M acneil (1980), nossa principal meta é desenvolver um arcabouço para o desenvolvimento de relacionamentos compradorvendedor. Enfatizamos três importantes ressalvas. Primeiramente, embora todas as transações apresentem algumas propriedades relacionais, é razoável conside- 


\section{F. ROBERT DWYER •PAUL H. SCHURR •SEJO OH}

rar boa parte delas como "praticamente singulares". Em segundo lugar, há conjuntos bilaterais de custos e benefícios na troca relacional; uma associação durável não é necessariamente desejável. Em terceiro lugar, como as origens conceituais e empíricas do modelo são ecléticas, e portanto estranhas ao marketing, o modelo é altamente propositivo.

A metáfora conjugal parece parcimoniosa e criativa. Ao dirigir a atenção da pesquisa ao processo inerentemente diádico do poder e da barganha, ela aponta a confiança como expectativa central específica, e sublinha nossa ignorância a respeito do desenlace. $\mathrm{Na}$ práti$\mathrm{ca}$, o modelo afirma e sugere diversas rotas de conduta de marketing de relacionamento. Parece-nos difícil encontrar algo mais próximo do cerne do marketing.

\section{NOTA}

${ }^{1}$ Buckley (1967) emprega os termos poder "legítimo" e "ilegítimo" onde empregamos "justo" e "injusto". A terminologia que escolhemos tem por objetivo evitar confusão com a taxonomia das fontes de poder (perito, referente, legítimo, etc.) de French e Raven (1959), que tem sido freqüentemente usada na pesquisa de vendas e de canais (cf. Gaski, 1986; Spiro e Perreault, 1979).

Este artigo é de propriedade exclusiva da American Marketing Association, tanto quanto sua licença para uso, e é protegido pelo Copyright e pelas leis de propriedade intelectual. É um material destinado a uso pessoal e não comercial. Qualquer outro tipo de uso deste artigo é estritamente proibido. 0 usuário não poderá modificar, publicar, transmitir, participar na transferência ou na venda do material, reproduzir, criar trabal hos derivados (inclusive material didático) deste, distribuir, realizar apresentação ou fazer qualquer utilização do seu conteúdo, inteiro ou em partes. Este artigo foi traduzido objetivando expressamente esta publicação. A American Marketing Association não assumirá nenhuma responsabilidade por erros de interpretação causados pela tradução. 0 artigo "Developing buyer-seller relationships", dos autores F. Robert Dwyer, Paul H. Schurr e Sejo Oh, foi originalmente publicado no Journal of Marketing, vol. 51 (April 1987), p. 1127 , e reproduzido com sua autorização.

\section{REFERÊNCIAS BIBLIOGRÁFICAS}

ACHROL, R. S.; REVE, T.; STERN, L. W. The environment of marketing channel dyads: a framework for comparative analysis. Journal of Marketing, v. 47, n. 4, 55-67, 1983.

ADVERTISING AGE. Citicorp boosts results by mixing media, 27 Jan. 1986. p. 52-53.
ALDERSON, W. Marketing Behavior and Executive Action. Homewood, IL: Richard D. Irwin, 1957.

ALDERSO N, W. Dynamic Marketing Behavior. Homewood, IL: Richard D. Irwin, 1965.

ALTMAN, I.; TAYLOW, D. A. Social Penetration: The Development of Interpersonal Relationships. New York: Holt, Rinehart and Winston, 1973.

ANDERSON, J. C.; NARUS, J. A. A model of the distributor's perspective of distributor-manufacturer working relationships. Journal of M arketing, $v$. 48, p. 72-74, 1984.

ANSOFF, J. I. Strategies for diversification. Harvard Business Review, v. 35 , n. 5, p. 113-124, 1957.

ARNDT, J. Toward a concept of domesticated markets. Journal of Marketing, v. 43, n. 4, p. 69-75, 1979.

ARNDT, J. The political economy paradigm: foundation for theory building in the marketing. Journal of Marketing, v. 47, n. 4, p. 55-54, 1983.

ASSAEL, H. Constructive role of interorganizational conflict. Administrative Science Quarterly, v. 14, n. 4, p. 573-582, 1969.

BAGOZZI, R. P. Marketing as exchange. Journal of M arketing, v. 39, n. 4, p. 32-39, 1975.

BAGOZZI, R. P. Toward a formal theory of marketing exchanges. In: FERRELL, O. C.; BROWN, S. W.; LAMB, C. W. (Eds.). Conceptual and Theoretical Developments in Marketing. Chicago: American Marketing Association, 1979. p. 431-437.

BAXTER, L. A. Self-disclosure as a relationship disengagement strategy. Human Communication Research, v. 5, p. 215-222, 1979.

BAXTER, L. A. Relationship disengagement: an examination of the reversal hypothesis. Western Journal of Speech Communication, v. 47, n. 2, p. 85-98, 1983.

BAXTER, L. A. Accomplishing relationship disengagement. In: DUCK, S.; PERLMAND, D. (Eds.). Understanding Personal Relationships. Beverly Hills, CA: Sage, 1985. p. 243-265.

BAXTER, L. A.; PHILPOTT, J. Attribution-based strategies for initiating and terminating relationships. Communication Quarterly, v. 30, n. 3, 217224, 1982.

BLAU, P. M. Exchange and Power in Social Life. New York: John Wiley \& Sons, 1964.

BLOCH, P. H.; GRADY, D. B. Product involvement as leisure behavior. In: KINNEAR, T. C. (Ed.). Advances in Consumer Research. Ann Arbor, MI: Association for Consumer Research, 1984.

BLOOM, B. L.; ASHER, S. J.; WHITE, S. W. Marital disruption as a stressor: a review and analysis. Psychological Bulletin, v. 85, n. 4, p. 867-894, 1978.

BRICKMAN, P. Social Conflict. Lexington, MA: D.C. Heath, 1974. 


\section{RAE CLÁSSICOS •DESENVOLVIMENTO DOS RELACIONAMENTOS ENTRE COMPRADOR E VENDEDOR}

CLOPTON, STEPHEN W. Seller and buying firm factors affecting industrial buyers' negotiation behavior and outcomes. Journal of Marketing Research, v. 21, p. 39-53, 1984.

COZBY, P. L. C. Self-disclosure: a literature review. Psychological Bulletin, v. 79, n. 2, p. 73-91, 1973.

DAHL, R. A. The concept of power. Behavioral Science, v. 2, n. 3, p. 201215, 1957

DAVIS, J. D.; SKIN NER, A. E. G. Reciprocity of self-disclosure in interviews: modeling or social exchange? Journal of Personality and Social Psychology, v. 29, p. 779-84, 1974.

DAY, G. S.; WENSLEY, R. Marketing theory with a strategic orientation. Journal of Marketing, v. 47, n. 4, p. 79-89, 1983.

DUCK, S. W. A Topography of relationship disengagement and dissolution. In: DUCK, S.; GILMOUR, R. (Eds.). Personal Relationships, 4: Dissolving Personal Relationships. New York: Academic Press, 1982.

DWYER, F. R. Are two better than one? Bargaining behavior and outcomes in an asymmetrical power relationship. Journal of Consumer Research, $v$. 11, n. 2, p. 680-683, 1984.

DWYER, F. R.; DORN OFF, R. J. The Congruency of Manufacturer Redress Actions and Consumer Redress N orms and Expectations. In: BERN HARDT, K. et al. (Ed.). Educators' Conference Proceedings. Chicago: American Marketing Association, 1981, p. 162-165.

DWYER, F. R.; WALKER JR., O. C. Bargaining in an asymmetrical power structure. Journal of Marketing, v. 45, n. 1, p. 104-115, 1981.

EKCH, P. P. Social Exchange: The Two Traditions. Cambridge, MA: Harvard Business Press, 1974.

EMERSON, R. M. Power dependence relations. American Sociological Review, V. 27, n. 1, p. 31-41, 1962.

FERBER, R. The expanding role of marketing in the 1970s. Journal of Marketing, v. 34, n. 1, p. 29-30, 1970.

FOX, A. Beyond Contract: Work Power and Trust Relations. London: Faber, 1974.

FRAZIER, G. L. Interorganizational exchange behavior: a broadened perspective. Journal of Marketing, v. 47, n. 4, p. 68-78, 1983a.

FRAZIER, G. L. On the measurement of interfirm power in channels of distribution. Journal of M arketing Research, v. 20, n. 2, p. 158-166, 1983b.

FRENCH, J.; RAVEN, B. The basis of social power. In: CARTWRIGHT, D. (Ed.). Studies in Social Power. Ann Arbor, MI: University of Michigan, 1959. p. 150-167.

GASKI, J. F. The theory of power and conflict in channels of distribution. Journal of Marketing, v. 48, n. 3, p. 9-12, 1984.

GASKI, J. F. Interrelations among a channel entity's power sources: impact on the exercise of reward and coercion on expert, referent and legitimate power sources. Journal of M arketing Research, v. 23, p. 62-77, 1986.
GOLDBERG, V. P. The law and economics of vertical restrictions: a relational perspective. Texas Law Review, v. 58, p. 91-129, 1979.

GOLEMBIEWSKI, R. T.; MCCONKIE, M. The centrality of interpersonal trust in group processes. In: COO PER, C. L. (Ed.). Theories of Group Process. New York: John Wiley \& Sons, 1975.

HARRIS, L.; ASSOCIADOS. Consumerism at the Crossroads, a Study Conducted for Sentry Insurance. Cambridge, MA: Marketing Science Institute, 1977.

HILL, C. T.; RUBIN , Z.; PEPLAU, L. A. Breakups before marriage: the end of 103 affairs. Journal of Social Issues, v. 32, n. 1, p. 147-168, 1976.

HIRSCHMANN, A. O. Exit, Voice and Loyalty. Cambridge, MA: Harvard University Press, 1970

HUNT, S. D. General theories and the fundamental explanada of Marketing. Journal of Marketing, v. 47, n. 4, p. 9-17, 1983a.

HUNT, S. D. Marketing Theory: The philosophy of Marketing Science. Homewood, IL: Richard D. Irwin, 1983b.

JACKSON, B. B. Winning and Keeping Industrial Customers: The Dynamics of Customer Relationships. Lexington, MA: D.C. Heath, 1985.

JOHN, G. An empirical investigation of some antecedents of opportunism in a marketing channel. Journal of M arketing Research, v. 21, n. 3, p. 278 289, 1984.

JOHNSTON, W. J.; BONOMA, T. V. Reconceptualizing industrial buying behavior: toward improved research approaches. In: GREENBERG, B. A.; BELLENGER, D. N. (Eds.). Contemporary Marketing Thought. Chicago: American Marketing Association, 1977. p. 247-251.

KESLER, L. Steak company welcomes customers' grilling. Advertising Age, p. 36-37, Oct. 1985.

KNAPP, M. L. Nonverbal Communication in Human Interaction. New York: Holt, Rinehart and Winston, 1978.

KOTLER, P. A generic concept of marketing. Journal of M arketing, v. $36, n$. 2, p. 46-54, 1972.

KOTLER, P.; LEVY, S. J. Broadening the concept of marketing. Journal of Marketing, v. 33, n. 1, p. 10-15, 1969.

KOTLER, P.; ZALTMAN, G. Social marketing: an approach to planned social change. Journal of Marketing, v. 35, n. 3, p. 3-12, 1971.

LAFRANCE, M.; MAYO, C. M oving Bodies: N onverbal Communication in Social Relationships. Monterey, CA: Brooks/Cole, 1978.

LEIGH, T. W.; RETHANS, A. J. A script-theoretic analysis of industrial purchasing behavior. Journal of Marketing, v. 48, n. 4, p. 22-32, 1984. 


\section{F. ROBERT DWYER •PAUL H. SCHURR •SEJO OH}

LEVINGER, G.; SNOOK, J. D. Attraction in Relationship: A New Look at Interpersonal Attraction. Morristown, NJ: General Learning Press, 1972.

LEVITT, T. The Marketing Imagination. N ew York: The Free Press, 1983.

LOTT, A. J.; LOTT, B. E. The role of reward in the formation of positive interpersonal attitudes. In: HUSTON , T. L. (Ed.). Foundation of Interpersonal Attraction. New York: Academic Press, 1974.

LUCK, D. Broadening the concept of marketing: too far. Journal of M arketing, v. 33, n. 3, p. 53-55, 1969

LUCK, D. Social marketing: confusion compounded. Journal of M arketing, v. 38, n. 4, p. 70-72, 1974.

MACNEIL, I. R. Contracts: adjustment of long-term economic relations under classical, neoclassical and relational contract law. Northwestern University Law Review, v. 72, p. 854-902, 1978.

MACNEIL, I. R. The N ew Social Contract, An Inquiry into M odern Contractual Relations. New Haven, CT: Yale University Press, 1980.

MCCALL, G.; SIMMONS, J. L. Identities and Interactions. New York: The Free Press, 1966

MCCALL, M. M. Courtship as social exchange: some historical comparisons. In: FARBER, B. (Ed.). Kinship and Family Organization. N ew York: John Wiley \& Sons, 1966.

MIILLER, G.; PARKS, M. Communication in dissolving relationships. In: DUCK, S. W. (Ed.). Personal Relationships, 4: Dissolving Personal Relationships, New York: Academic Press, 1982.

MONSANTO CO . v. Spray-Rite Service Corp. 104 S. Ct. 1464, 684, F. 2d 1226. 1984.

MORRISON, D. G.; CHEN, R. D. H.; KARPIS, S. L.; BRITNEY, K. E. A. Modeling retail customer behavior at Merril Lynch. M arketing Science, $v .1$, p. $123-42,1982$

OLIVER, R. L. A Cognitive model of the antecedents and consequences of satisfaction decisions. Journal of Marketing Research, v. 17, n. 4, p. 460469,1980

PETERS, T.; AUSTIN, N. Managing by walk-around. California Management Review, v. 28, n. 1, p. 9-34, 1985.

PONDY, L. R. Organizational conflict: concepts and models. Administrative Science Quarterly, v. 12, n. 2, p. 296-320, 1967.

PRUITT, D. G. N egotiation Behavior. N ew York: Academic Press, 1981.

RAIFFA, H. The Art and Science of Negotiation. Cambridge, MA: Harvard University Press, 1982.
RAVEN, B. H.; KRUGLANSKI, A. W. Conflict and Power. In: SWINGLE, P. (Ed.). The Structure of Conflict. New York: Academic Press, 1970. p. 69109.

ROSENBERG, L. J. A new approach to distribution conflict management. Business Horizons, v. 17, n. 5, p. 67-74, 1974.

ROTTER, J. B. A new scale for the measurement of interpersonal trust. Journal of Personality, v. 35, n. 4, p. 651-655, 1967.

SCANZONI, J. Social exchange and behavioral interdependence. In: BURGESS, R. L.; HUSTON, T. L. (Eds.). Social Exchange in Developing Relationships. New York: Academic Press, 1979.

SCANZO NI, J. Sexual Bargaining: Power Policies in the American Marriage. Chicago: The University of Chicago Press, 1982.

SCHELLING, T. The Strategies of Conflict. Cambridge, MA: Harvard University Press, 1960.

SCHURR, P. H.; OZANNE, J. L. Influences on exchange processes: buyers' preconceptions of a seller's trustworthiness and bargaining toughness. Journal of Consumer Research, v. 11, n. 4, p. 939-953, 1985.

SECORD, P. F.; BACHMAN, C. W. Social Psychology. New York: McGrawHill, 1974.

SHAPIRO, B. Close encounters of the fourth kind: the latest selling evolution. Working paper. Harvard Business School, 1985.

SMITH, R. E.; SWINYARD, W. R. Information response models: an integrated approach. Journal of Marketing, v. 46, n. 1, p. 81-93, 1982.

SPEKMAN, R. E; STRAUSS, D.; SMITH, R. B. Antecedents of collaborative relations between buyers and sellers: an exploratory investigation from the buyer's perspective. University of Maryland, 1985. mimeo.

SPIRO, R. L.; PERREAULT JR., W. D. Influence use by industrial salesmen: influence-strategy mixes and situational determinants. Journal of Business, v. 52, n. 2, p. 435-455, 1979.

STERN, L.; GORMAN, R. Conflict in distribution channels: an exploration. In: STERN, L. (Ed.). Distribution Channels: Behavioral Dimensions. N ew York: Houghton-Mifflin, 1969

STERN, L.; REVE, T. Distribution channels as political economies: a framework for comparative analysis. Journal of Marketing, v. 44, n. 3, p. $52-64,1980$

SULLIVAN, J.; PETERSO N, R. B. Factors associated with trust in JapaneseAmerican joint ventures. Management International Review, v. 22, n. 2, p. $30-40,1982$

SULLIVAN, J.; PETERSON, R. B.; KAMEDA, N.; SHIMADA, J. The relationship between conflict resolution approaches and trust: a cross cultural study. Academy of Management Journal, v. 24, n. 4, p. 803-815, 1981. 
SWAN, J. E.; NOLAN, J. J. Gaining customer trust: a commercial guide for the sal esperson. Journal of Personal Selling and Sales M anagement, v. 5, n. 2, p. 39-48, 1985.

SWAN, J. E.; TRAWICK, I. F.; SILVA, D. How industrial salespeople gain customer trust. Industrial Marketing Management, v. 14, n. 3, p. 203-211, 1985.

THIBAUT, J. W.; KELLEY, H, H. The Social Psychology of Groups. New York: John Wiley \& Sons, 1959.

THOMAS, K. Conflict and conflict management. In: DUN NETTE, M. D. (Ed.). Handbook of Industrial and Organizational Psychology. Chicago: Rand McNally, 1976. p. 889-935.

WEICK, K. The Social Psychology of Organizing. Reading, MA: AddisonWesley, 1979.
WEITZ, B. A. Effectiveness in sales interactions: a contingency framework. Journal of Marketing, v. 45, n. 1, p. 85-103, 1981.

WILLIAMSON, O. Markets and Hierarchies: Analysis and Antitrust Implications. New York: The Free Press, 1975.

WILLIAMSON, 0. Credible commitments: using hostages to support Exchanges. America Economics Review, v. 73, n. 4, p. 519-540, 1983.

WORCHEL, P. Trust and distrust. In: AUSTIN, W. B.; WORCHEL, S. (Eds.). Social Psychology and Intergroup Relations. Belmont, CA: Wadsworth, 1979.

ZAND, D. E. Trust and managerial problem solving. Administrative Science Quarterly, v. 117, n. 2, p. 229-239, 1972.

\section{Artigo convidado. Aprovado em 01.02.2006.}

\section{F. Robert Dwyer}

Professor da cadeira Joseph S. Stern de M arketing na University of Cincinnati.

Interesses de pesquisa nas áreas de Governança Interfirmas, Canais de Marketing, Relações Comprador-Vendedor, Marketing Direto.

E-mail: bob.dwyer@uc.edu

Endereço: University of Cincinnati, 430 Carl H. Lindner Hall, PO Box 210145, Cincinnati - Ohio, 45221-0145, U.S.A.

\section{Paul H. Schurr}

Professor de Marketing da School of Business - University at Albany (SUNY).

Interesses de pesquisa nas áreas de Desenvolvimento de Relacionamentos entre Negócios, N egociação e M arketing de Indústria de Alta Tecnologia.

E-mail: p.schurr@albany.edu

Endereço: School of Business, University at Albany (SUNY), 1400 Washington Ave. Albany - NY, 12222, U.S.A.

\section{Sejo Oh}

Professor de Marketing da Graduate School of Business Administration - Yonsei University. Interesses de pesquisa nas áreas de Desenvolvimento de Relacionamentos entre N egócios, Marketing. E-mail: sjoh@base.yonsei.ac.kr

Endereço: Graduate School of Business Administration, Yonsei University, Seoul 120-749, Korea. 